\title{
Production and Optimization of Xylanase and $\alpha$-Amylase from Non-Saccharomyces Yeasts (Pichia membranifaciens)
}

\author{
Hala A. Salah', Hanan A. Temerk ${ }^{2}$, Nivin A. Salah ${ }^{3}$, Saeed Rafa Zara Alshehri ${ }^{4}$, \\ Jazi A. Al-Harbi', Asmaa M.M. Mawad ${ }^{6}$, Khaled A. M. Khaled ${ }^{7}$, Abd El-Latif \\ Hesham $^{7 *}$ (D) and Karam A. Amein ${ }^{8}$ \\ ${ }^{1}$ Molecular Biology Department, National Research Centre, Cairo, Egypt. \\ ${ }^{2}$ Botany and Microbiology Department, Faculty of Science, South Valley University, Qena, Egypt. \\ ${ }^{3}$ Biochemistry Division, Department of Chemistry, Faculty of Science, Mansoura, University, Mansoura, Egypt. \\ ${ }^{4}$ College of Technology, Khamis Mushait, Saudi Arabia. \\ ${ }^{5}$ Ministry of Health, Saudi Arabia. \\ ${ }^{6}$ Botany and Microbiology Department, Faculty of Science, Assiut University, Assiut - 71516,Egypt. \\ ${ }^{7}$ Genetics Department, Faculty of Agriculture, Beni-Suef University, Beni-Suef - 62511, Egypt. \\ ${ }^{8}$ Genetics Department, Faculty of Agriculture, Assiut University, Egypt.
}

*Correspondence: hesham_egypt5@agr.bsu.edu.eg

(Received: November 05, 2020; accepted: February 13, 2021)

Citation: Salah HA, Temerk HA, Salah NA, et al. Production and Optimization of Xylanase and $\alpha$-Amylase from Non-Saccharomyces Yeasts (Pichia membranifaciens). J Pure Appl Microbiol. 2021;15(1):452-461. doi: 10.22207/JPAM.15.1.43

(C) The Author(s) 2021. Open Access. This article is distributed under the terms of the Creative Commons Attribution 4.0 International License which permits unrestricted use, sharing, distribution, and reproduction in any medium, provided you give appropriate credit to the original author(s) and the source, provide a link to the Creative Commons license, and indicate if changes were made. 


\begin{abstract}
The xylanolytic and amylolytic yeasts were qualitatively determined by Cong red xylan agar and soluble starch agar plates, respectively. The most xylanase and $\alpha$-amylase inducible strain (AUN-02) was selected and identified using PCR amplification of 26S rRNA gene and sequence analysis. The comparison of the alignment results and phylogenetic analysis of the sequences of the isolated yeast to published rRNA gene sequences in GenBank, confirmed the identification of the isolate as Pichia membranifaciens. Xylanase and $\alpha$-amylase production by isolated $P$. membranifaciens were investigated at different $\mathrm{pH}$ values (4-8), temperature degrees $\left(20-45^{\circ} \mathrm{C}\right)$, incubation time (1-7 days) and various substrates.A higher production of xylanase $(38.8 \mathrm{U} / \mathrm{mL})$ and $\alpha$-amylase $(28.7 \mathrm{U} / \mathrm{mL})$ was obtained after 4 days of fermentation of $P$. membranifaciens. Higher activity of xylanase $(36.83 \mathrm{U} / \mathrm{mL})$ and $\alpha$-amylase $(27.7 \mathrm{U} /$ $\mathrm{mL}$ ) was obtained in the fermentation of $P$. membranifaciens in a culture medium adjusted to $\mathrm{pH}$ 7.0. The optimum temperature showed maximum xylanase and $\alpha$-amylase activity $(42.6$ and $32.5 \mathrm{units} / \mathrm{mL}$, respectively) was estimated at $35^{\circ} \mathrm{C}$. The xylanase and $\alpha$-amylase activities of $P$. membranifaciens were estimated and compared for the different substrates tested. The strain revealed $100 \%$ relative activity of xylanase and $\alpha$-amylase on beechwood and potato starch, respectively. The affinity of enzymes towards substrate was estimated using $\mathrm{Km}$ values. The $\mathrm{Km}$ values of $x y l a n a s e$ and $\alpha$-amylase increased in the order of $\mathrm{pH}$ 's 7.0, 6.0 and $4.5(0.85,1.6$ and $3.4 \mathrm{mg} x y l a n / \mathrm{mL}$ and $0.22,0.43$ and $2.8 \mathrm{mg}$ starch/ $\mathrm{mL}$, respectively). the yeast $P$. membranifaciensis is suitable for produce neutral xylanase and $\alpha$-amylase enzymes. So, it could be used as a promising strain for production of these enzymes in industrial field.

Keywords: Amylase, neutral, Pichia membranifaciens, xylanase, yeast
\end{abstract}

\section{INTRODUCTION}

Biotechnology became an alternative and conventional trend in the fields of industry and analysis. The incorporation of biotechnology in these fields has many advantages includes production of desirable products which could be used in ingredient substitutions, alleviates the product yields, less energy consumption and ecofriendly ${ }^{1}$. The microbial enzymes meet the industrial demand and now a large number of them are commercially available ${ }^{2}$.

Following cellulose, xylan is the second most available renewable polysaccharide. Xylanases are hydrolytic enzymes that cleave the $\beta-1,4$ glycosidic bonds of xylan. They are applied for the production of hydrolysates in food and beverage industries, bioethanol and azodye removal ${ }^{3}$. These are used to enhance the nutrients digestibility in animal feed ${ }^{4}$ as well as used for biobleaching of kraft pulp in pulp and paper industry ${ }^{5}$. It has also been reported that xylanases play a role in a production of natural sweetener ${ }^{6}$. The bioproduction of xylanases was performed by bacteria, actinomycetes, yeast and filamentous fungi ${ }^{7}$. However, xylanolytic yeasts have not been cited frequently ${ }^{8,9}$; such as Pichia stiptis ${ }^{10}$, Cryptococcus, Fellomyces 11 and Candida ${ }^{3}$. The optimum activity of fungal xylanases is neutral or slightly acidic $\mathrm{pH}^{\prime} \mathrm{s}^{12}$.

$\alpha$-Amylases (E.C.3.2.1.1) are enzymes that catalyze the hydrolysis of internal $\alpha-1,4$-glycosidic linkages in starch ${ }^{13}$ to produce dextrin, maltose and glucose units. The enzymes are applied in starch liquefaction, paper, improving textile fabrics and preparing starch coatings of paints industries. In addition, $\alpha$-amylases are applied the detergent industry, breweries and in the production of syrups. The use of amylase has grown in many ways, including scientific, pharmaceutical and analytical chemistry ${ }^{2,14,15}$. Different types of amylases can be produced by various organisms ${ }^{16}$. However, microbial amylase is preferred due to its biochemical versatility, higher production rate, stability, and availability by large number of microbial species. $\alpha$-Amylases is the major type of microbial amylases that produced by fungi, yeasts and bacteria ${ }^{1}$. The production of $\alpha$-amylase by submerged fermentation $(\mathrm{SmF})$ and solid-state fermentation (SSF) has been depend on some of physicochemical factors such as $\mathrm{pH}$, temperature 
and moisture ${ }^{17,18}$. The $\mathrm{pH}$ is very effective in the industry, where $\alpha$-amylases used in starch industry are stable at low $\mathrm{pH}$ and in the detergent industry the high $\mathrm{pH}$ is required ${ }^{19}$.

Therefore, this study aimed to isolate xylanolytic and amylolytic yeast strain and detect the optimum parameter for xylanase any amylase production by isolated yeast.

\section{MATERIALS AND METHODS}

Yeast isolation, and purification

A weigh of $5 \mathrm{~g}$ of soil samples that were collected from various farmlands in Assiut region, Egypt were suspended on $45 \mathrm{~mL}$ of sterilized distilled water to form soil spore suspension. Ten-fold serial dilutions of spore suspension were prepared. An aliquot of $100 \mu \mathrm{L}$ was withdrawn and plated on sterilized yeast extract peptone dextrose (YEPD) agar plates as the method described by ${ }^{20}$. The plates were incubated at $28^{\circ} \mathrm{C}$ for $72 \mathrm{~h}$. The grown colonies were picked up, purified and preserved in YEPD slant agar tubes at $4^{\circ} \mathrm{C}$.

Qualitative screening of xylanase and amylase production

For propagation of inoculum, the pure yeast culture was inoculated in liquid medium containing per liter glucose; $10 \mathrm{~g}, \mathrm{NaNO}_{3} ; 0.3 \mathrm{~g}$, $\mathrm{KH}_{2} \mathrm{PO}_{4} ; 3 \mathrm{~g}, \mathrm{MgSO}_{4} ; 0.3 \mathrm{~g}$ and yeast extract; $\mathrm{g}$ at $28^{\circ} \mathrm{C}, 140 \mathrm{rpm}$, for $48 \mathrm{~h}$. Xylanase production was qualitatively confirmed by formation of clear halo zones around growing colonies that inoculated on Congo red-beechwood xylan (1\%) agar plates after washing with $1 \mathrm{M} \mathrm{NaCl}$. While the screening of amylase production was qualitatively confirmed by formation of clear halo zones around growing colonies that inoculated on soluble starch (1\%) agar plates after washing with iodine solution $(10 \%)^{21}$.

Molecular identification of Xylanase and $\alpha$-amylase producing yeast

Total genomic DNA from xylanase and $\alpha$-amylase producing yeast was isolated, according to 20. primers NL1 (5'-GCATATCAATAAGCGGAGGAAAAG-3') and NL4 (5'-GGTCCGTGTTTCAAGACGG-3') ${ }^{22}$ were used to amplify 26S rDNA D1/D2 domain region. PCR was carried out in a total volume of $50 \mu \mathrm{l}$ consisting GoTaq green master mix (Promega, Madison, WI, USA), $1 \mu \mathrm{L}$ DNA sample, and $1 \mu \mathrm{L}$ of every primer $(0.5 \mathrm{mM})^{23}$. The amplification was performed under the following conditions: the denaturation at $95^{\circ} \mathrm{C}$ for $5 \mathrm{~min}$, accompanied by 36 cycles at $94^{\circ} \mathrm{C}$ for $2 \mathrm{~min}, 52^{\circ} \mathrm{C}$ for $1 \mathrm{~min}, 72^{\circ} \mathrm{C}$ for $2 \mathrm{~min}$; the extension at $72^{\circ} \mathrm{C}$ for $7 \mathrm{~min}$; and then sustained at $4^{\circ} \mathrm{C}$. A volume of $5 \mu \mathrm{l}$ of PCR products was then analyzed using $1.5 \% 0.5 \times$ TBE agarose gel electrophoresis. A 100-bp DNA ladder has been used as a marker. The gel was stained with Ethidium bromide and images were captured under ultraviolet light.

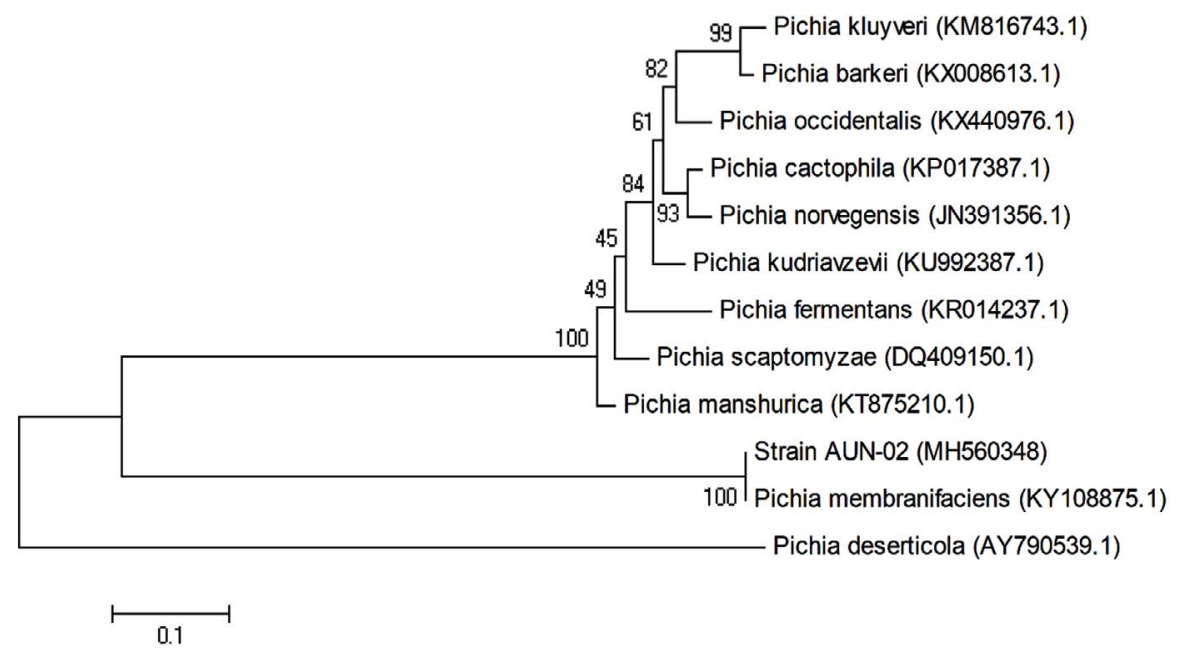

Fig. 1. Phylogenetic relationships between strain AUN-02 and 26S rRNA gene sequences from other published Pichia spp. GenBank accession numbers are given in parentheses. 
Purification of PCR products and determination of 26S rRNA gene D1/D2 domain sequences

With a Takara agarose gel DNA purification package, the PCR products ( $600 \mathrm{bp}$ ) were purified, and then sequenced using $A B I 3730$ automated sequencer by Macrogen in both directions (Seoul, Korea).

Phylogenetic analysis and comparisons of 265 rRNA gene D1/D2 domain sequences

The 26S rRNA gene D1/D2 domain sequences yeast generating xylanase and $\alpha$-amylase were searched in the GenBank and matched with recognized 26S rRNA gene sequences at the National Center for Biotechnology Information (http://www.ncbi.nlm.nih.gov/BLAST/) using the basic local alignment search tool (BLAST). To identify the isolated yeast, percent identity scores were generated. The phylogenetic tree was also established using MEGA version 4.0 with the neighbor-joining algorithm and JukesCantor distance estimation, with 1,000 bootstrap replicates, to validate the taxonomic classification of the xylanase and $\alpha$-amylase producing yeast.

Quantitative Determination of enzymes activities A percentage of $10 \% \mathrm{~V} / \mathrm{V}$ of propagated culture were inoculated on new sterilized previously mentioned agar media supplemented with birchwood xylan or soluble starch instead of glucose and incubated at $150 \mathrm{rpm}$ and $30^{\circ} \mathrm{C}$ for 7 days $^{24}$. Substrates used were beechwood xylan and starch for xylanase and $\alpha$-amylase, respectively. One- $\mathrm{mL}$ of each culture sample was centrifuged at $13000 \mathrm{rpm}, 4^{\circ} \mathrm{C}$, and the supernatants (enzyme crude extract) were stored at $-20^{\circ} \mathrm{C}$ for analysis. Xylanase and $\alpha$-amylase activities were assayed by determining the liberated reducing end products using xylose and maltose as standards, respectively ${ }^{25}$. one percent of substrate, $0.05 \mathrm{M}$ sodium acetate buffer $\mathrm{pH}$ 5.5 and $0.1 \mathrm{~mL}$ enzyme crude extract were used in the reaction mixture $(0.5 \mathrm{~mL})$ contained. Assays were performed for an hour at $37^{\circ} \mathrm{C}$. A volume of $0.5 \mathrm{~mL}$ 3,5-dinitrosalicylic acid (DNS) reagent was applied to each tube. Then the reaction mixture was vortexed and boiled in a water bath for $10 \mathrm{~min}$. The absorbance was determined at $560 \mathrm{~nm}$ after cooling to room temperature. The reducing sugar was estimated from the standard calibration curve equation using xylose and D-glucose for xylanase and amylase, respectively. The quantity of enzyme that released one $\mu \mathrm{mol}$ of reduced sugar per min under optimum assay condition is defined as oneunit enzyme activity.

\section{Optimization factors for xylanase and $\alpha$-amylase production}

The yeast isolate was cultivated in the minimal basal slat medium (MBS-g/L) $\mathrm{NaNO}_{3}$; $3 \mathrm{~g}, \mathrm{MgSO}_{4} ; 0.3 \mathrm{~g}, \mathrm{KH}_{2} \mathrm{PO}_{4} ; 0.3 \mathrm{~g}$ supplemented with birchwood (1\%) or soluble starch (1\%) for 7 days at $150 \mathrm{rpm}$ and $30^{\circ} \mathrm{C}$. An aliquot of $1 \mathrm{~mL}$

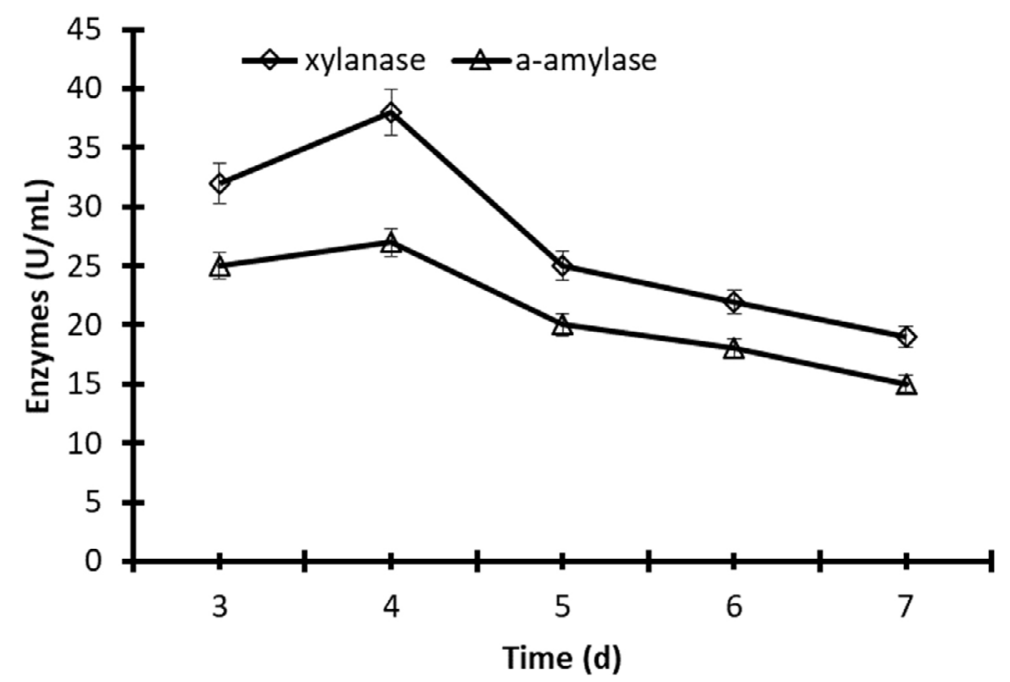

Fig. 2. Production of xylanase and $\alpha$-amylase by fermentation of Pichia membranifaciens AUN-02 in Erlenmeyer flasks at $30^{\circ} \mathrm{C}$ and $150 \mathrm{rpm}$. The data were considered as means \pm S.E. $(n=3)$. 
was withdrawn each $24 \mathrm{~h}$ interval to perform the enzymes assay in order to determine the optimum incubation time for maximum production of xylanase and $\alpha$-amylase.

The effect of temperature on the studied enzymes production was determined by cultivating the isolate in (MBS) medium at varying temperatures $\left(25,30,35,40\right.$ and $\left.45^{\circ} \mathrm{C}\right)$ accompanied by xylanase and $\alpha$-amylase assays at optimum incubation period ${ }^{26}$. Similarly, optimal $\mathrm{pH}$ for the xylanase production was investigated by cultivating the yeast isolate in the medium with $\mathrm{pH}$ changed to $4.0,5.0,6.07 .0$ or 8.0 at the optimum temperature ${ }^{27,28}$.

Similarly, the effect of the substrate source 1\% (birchwood, oat split and beechwood xylan) and (potato starch, glycogen, amylose, $\alpha$-Cyclodextrin and $\beta$-Cyclodextrin) on the activity of xylanase and $\alpha$-amylase, respectively were investigated at optimum time, temperature and $\mathrm{pH}$. All determinations were performed in triplicate.

Table 1. Km values $(\mathrm{mg} / \mathrm{mL})$ of xylanase and $\alpha$-amylase enzymes produced from Pichia membranifaciens at different $\mathrm{pH}$ values. The data were considered as means \pm S.E. $(n=3)$

\begin{tabular}{ccc}
\hline $\mathrm{pH}$ & $\begin{array}{c}\text { Xylanase } \\
(\mathrm{mg} / \mathrm{mL})\end{array}$ & $\begin{array}{c}\alpha \text {-amylase } \\
(\mathrm{mg} / \mathrm{mL})\end{array}$ \\
\hline 7.0 & $0.85 \pm 0.05$ & $0.22 \pm 0.01$ \\
6.0 & $1.6 \pm 0.1$ & $0.43 \pm 0.02$ \\
4.0 & $3.4 \pm 0.18$ & $2.8 \pm 0.13$
\end{tabular}

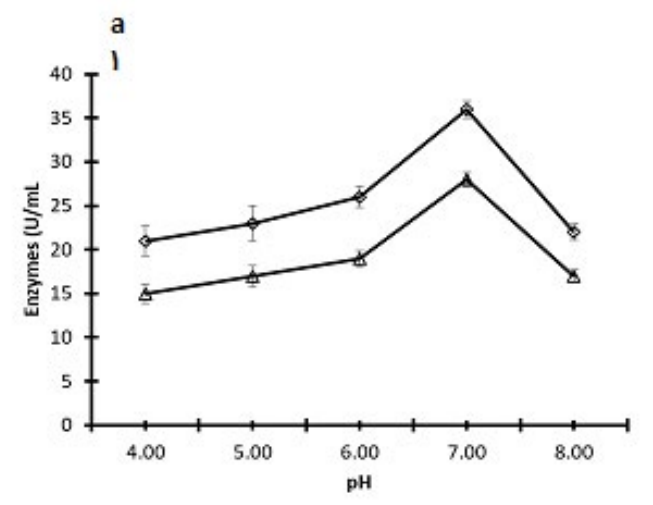

\section{Statistical analysis}

The data were statistically analyzed by a one-way ANOVA. The data were considered as means \pm S.E. $(n=3)$.

\section{RESULTS}

Isolation and selection of yeasts producing xylanase and $\alpha$-amylases

Twenty yeast isolates were collected from various soil samples in Assiut region, Egypt. All isolated yeasts were screened for xylanase and $\alpha$-amylase production and one promising isolate designated as AUN-02 was selected. The AUN02 isolate exhibited large halo zone around its growing colony on xylan supplemented medium colored with Congo red and soluble starch stained with iodine solution.

Yeast Identification using 26S rRNA gene D1/D2 Region Sequencing and Phylogenetic Analyses

The phylogenetic location of yeast AUN-02 isolate was established and determined through molecular techniques. The alignment of $26 \mathrm{~S}$ rRNA gene sequences of the yeast AUN02 with the reported 26S rRNA sequences from GenBank using BLAST indicates $100 \%$ with Pichia membranifaciens Phylogenetic tree was developed for AUN-02 isolate along with other GenBank sequences of the same genus. As shown in (Fig. 1), strain AUN-02 and Pichia membranifacienssh are a node with zero, or near zero, evolutionary distance of separation. Therefore, strain AUN-02 was identified as Pichia membranifaciens.

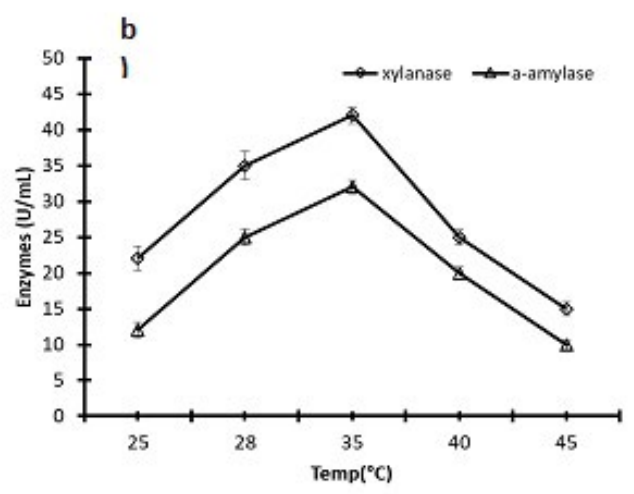

Fig. 3. Effect of the $\mathrm{pH}$ of the culture medium and the temperature of fermentation of Pichia membranifaciens AUN-02 on the production of xylanase and $\alpha$ - amylase. The data were considered as means \pm S.E. $(n=3)$. 
Accession number of the nucleotide sequences

In this analysis, nucleotide sequences of the xylanase and $\alpha$-amylase producing AUN02 yeast were recorded in the DDBJ (www. ddbj.nig.ac.jp/), EMBL (www.embl.de/), and GenBank (http://www.ncbi.nlm.nih.gov/ genbank/) databases of nucleotide sequences under accession number: MH560348.

Kinetics of xylanase and $\alpha$-amylase production by the yeast Pichia membranifaciens AUN-02

The time of incubation has a significant impact on the stability of enzymes. A higher production of xylanase $(38.8 \mathrm{U} / \mathrm{mL})$ and $\alpha$-amylase $(28.7 \mathrm{U} / \mathrm{mL})$ was obtained after 4 days of fermentation of the yeast Pichia membranifaciens in flasks stirred at $30^{\circ} \mathrm{C}$ and $150 \mathrm{rpm}$. After 5 days of fermentation, the activity of xylanase and $\alpha$-amylase decreased to 31.2 and $26 \%$, respectively (Fig. 2). Moreover, the significant decrease of xylanase and $\alpha$-amylase to 44.5 and $40.6 \%$ after 7 days compared to the stability at 4 days of incubation (Fig.2).

Characterization of $\mathrm{pH}$ and temperature profile of xylanase and $\alpha$-amylase activity in crude enzyme extract

The effect of $\mathrm{pH}$ on the productivity of xylanase and $\alpha$-amylase from Pichia membranifaciens strain AUN-02 was illustrated in (Fig.3a). The activities of enzymes were dramatically increased from acidic $\mathrm{pH} 4.0$ to neutral pH 7.0. Higher activity of xylanase (36.83 U $/ \mathrm{mL}$ ) and $\alpha$-amylase $(27.7 \mathrm{U} / \mathrm{mL}$ ) was obtained in the fermentation of Pichia membranifaciens AUN02 in a culture medium adjusted to $\mathrm{pH}$ 7.0. The activity was then significantly reduced to 21.2 and $16.3 \mathrm{U} / \mathrm{mL}$ for xylanase and $\alpha$-amylase at alkaline $\mathrm{pH} 8.0$, respectively. The results demonstrated that the yeast $P$. membranifaciensis suitable for production of acidic and neutral xylanase and $\alpha$-amylase enzymes although the latter being better.

The temperature range between 25 and $45^{\circ} \mathrm{C}$ was used to study the influence of temperature on the studied enzymes (Fig. 3b). The temperature profile revealed that, the optimum temperature that showed maximum xylanase and $\alpha$-amylase activity (42.6 and 32.5 units $/ \mathrm{mL} / \mathrm{min}$, respectively) was estimated at $35^{\circ} \mathrm{C}$. However, the xylanase and $\alpha$-amylase activities showed significant $50 \%$ decrease at 25 and $45^{\circ} \mathrm{C}$, compared to the values at $35^{\circ} \mathrm{C}$

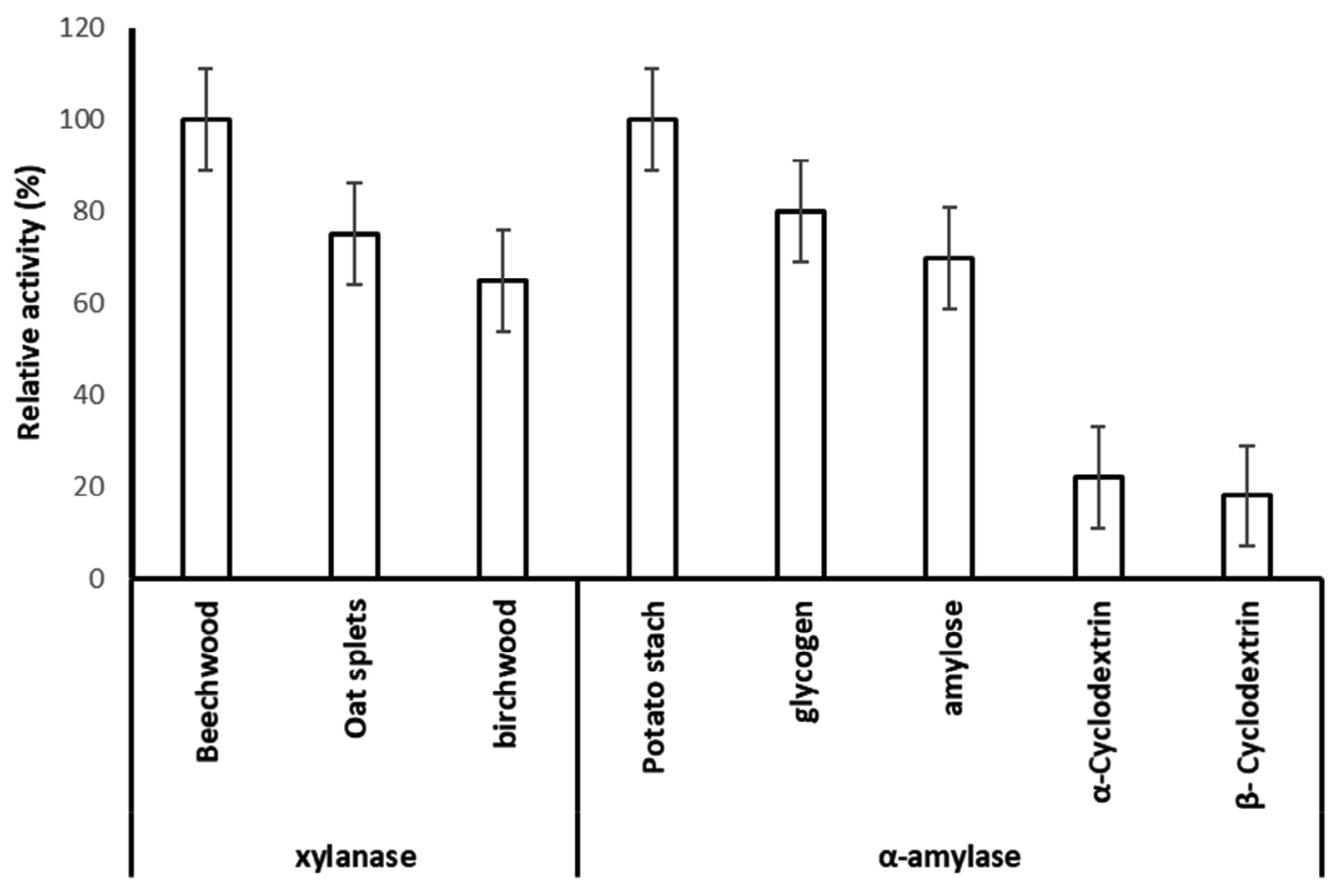

Fig. 4. Substrate specificity of xylanase and $\alpha$-amylase that produced from Pichia membranifaciens. 
Assessment of xylanase and $\boldsymbol{\alpha}$-amylase activity on different substrates

In order to determine the extracellular xylanolytic and amylolytic potential of $P$. membranifaciens AUN-02, were grown in media containing (birchwood, oat split or beechwood xylan) and (potato starch, glycogen, amylose, $\alpha$-Cyclodextrin and $\beta$-Cyclodextrin) ( $1 \% \mathrm{w} / \mathrm{v}$ carbohydrate content) for 7 days at $28^{\circ} \mathrm{C}$. The xylanase and amylase activities of crude enzyme extracts from $P$. membranifaciens AUN-02 were estimated and compared for the different substrates tested (Fig. 4). The strain revealed $100 \%$ relative activity of xylanase and $\alpha$-amylase on beechwood and potato starch, respectively. It also exhibited 75 and $65 \%$ of relative xylanase activity on oat spelt and birchwood xylan, respectively. On the other hand, it exhibited no significant difference in the relative $\alpha$-amylase activity on glycogen and amylose (80 and $70 \%$, respectively). Comparatively, the significant decrease in $\alpha$-amylase activity was detected on $\alpha$-Cyclodextrin and $\beta$-Cyclodextrin (22 and 18\%), respectively.

\section{Enzymes kinetics at different $\mathrm{pH}$ values}

The $\mathrm{Km}$ values of xylanase and $\alpha$-amylase from Pichia mebranifaciens strain AUN-02 at different $\mathrm{pH}$ values are shown in Table 1 . The $\mathrm{Km}$ values of xylanase and $\alpha$-amylase increased in the order of pH's 7.0, 6.0 and $4.5(0.85,1.6$ and 3.4 $\mathrm{mg}$ xylan/mL and $0.22,0.43$ and $2.8 \mathrm{mg}$ starch/ $\mathrm{mL}$, respectively). The low $\mathrm{Km}$ indicated the high affinity of substrate to the enzyme. Therefore, the xylanase and $\alpha$-amylase produced at $\mathrm{pH} 7.0$ had high affinity toward xylan and starch.

\section{DISCUSSION}

Xylanase along with different enzymes are important for the lignocellulosic based biorefineries to convert complex substrates. Amylases and xylanases are amongst the most studied enzymes that attracted worldwide attention due to their physiological and biotechnological applications ${ }^{29}$.

Screening xylanase and amylase with Congo red and lodine solution, respectively are common methods in which the Congo red dye remains attached to xylan polymer while the iodine solution forms a blue complex with starch polymer. So, the formation of the halo zone around the growing colonies is indicating the hydrolysis of xylan or starch which are directly related to the region of action of the corresponding enzymes ${ }^{21,30}$. Relatively less abundance 23 strains of yeasts out of 119 of yeasts strains has been reordered positive xylanolytic activity as described by ${ }^{31}$.

Xylanase producing yeasts can be used in biorefineries for subsequent steps. They are however, still the focus of intensive research. The xylanolytic and amylolytic yeast strain AUN02 was isolated from farmland in this sense because it consists of various types of cellulosic, hemicellulosic, and lignocellulosic matters.

As a valuable identification tool, The 26S rRNA gene D1/D2 domain has acquired recognition in yeast taxonomy ${ }^{32-34}$. D1/D2 domain sequence databases are available for all currently recognized ascomycetous and basidiomycetous yeasts. This makes it much easier to classify species and serves as a valid and functional criterion for identification of most recognized yeast ${ }^{22,34,35}$. Yeast strain Pichia membranifaciens was isolated from different sources and it has many biotechnological applications. 1,3-dihydroxyacetone producing $P$. membranifaciens was isolated from soil sample and identifies based on ITS rDNA gene sequence analysis ${ }^{36}$. Pichia membranifaciens was among the abundant yeast species that isolated from directly brined olives of Alorena ${ }^{37,38}$ reported the purified $1,4-\beta$-xylosidase from $P$. membranifaciens that has been cultivated on xylan as a substrate and this enzyme is used in the bioethanol production process.

xylanase showed optimum at or near mesophilic temperatures between $30-60^{\circ} \mathrm{C}^{7,13}$ and slightly acidic $\mathrm{pH}$. Similarly, the $\mathrm{pH}$ value for maximum production of $\alpha$-amylase by microorganisms ranged from 6.0 to $7.0^{39,40}$. Optimum neural $\mathrm{pH}$ was recorded for xylanase from Aspergillus caespitosus ( $\mathrm{pH}$ 6.5-7.0) ${ }^{41}$. At $\mathrm{pH}$ 4.5 , the maximum production of $\alpha$-amylase was detected for Trichoderma harzianum ${ }^{42}$. $\alpha$-amylase producing yeast strains such as Saccharomyces cerevisiae and $S$. kluyveri exhibited maximum enzyme production at $\mathrm{pH} 5.0^{43}$. The maximum amylase production from Bacillus cereus IND4 at $45^{\circ} \mathrm{C}$ on starch agar medium ${ }^{44}$, whereas maximum amylase production at moderate temperature $\left(30^{\circ} \mathrm{C}\right)$ from the fungal strain ${ }^{45}$.

Depending upon the substrates, xylanolytic enzymes are normally inducible 
under normal conditions. However, a few species demonstrate constitutive production of the enzyme and are consumed it as carbon sources ${ }^{46}$. In certain cases, xylan has been found to be the best inducer of xylanase production ${ }^{12}$. Xylan, is a high molecular weight polymer, that os unable to enter the microbial cell directly. Low molecular weight of xylan fragments induce the production if enzymes ${ }^{7}$. Xylanase induction can be performed on a number of low cost lignocellulosic ingredients, such as wheat bran, wheat straw, rice husk, rice bran, rice straw and corncob have been shown to be most appropriate substrates for fermentation in some microbes ${ }^{47}$.

The induction of $\alpha$-amylase production by microorganisms is stimulated by potato and corn starch, and soluble starch. The rate of hydrolysis by Bacillus sp. BCC 01-50 of soluble starch, wheat, potato, and corn starches at $1 \%$ concentration was $73.43,60.81,55.26$, and $67.81 \%{ }^{16}$.

The $\mathrm{Km}$ values of xylanase from $P$. membranifaciens were similar to Km's of xylanases from Anoxybacillus kamchatkensis (0.7 mg xylan/ $\mathrm{mL} ;{ }^{48}$ ) and Aspergillus ficuum AF-98 (Km $3.267 \mathrm{mg}$ xylan $\left./ \mathrm{mL} ;{ }^{49}\right)$. For the $\mathrm{Km}$ values of $\alpha$-amylase from P. membranifaciens, they similar to the $\mathrm{Km}$ values of $\alpha$-amylase from Cryptococcus flavus $(0.056 \mathrm{mg}$ starch $\left./ \mathrm{mL}^{50}\right)$ and Lipomyces kononenkoae CBS 5608 (Km 0.8 g starch/L; $\left.{ }^{51}\right)$.

It could be concluded that, the yeast isolate AUN-02 is a promising strain for production of xylanases and $\alpha$-amylase. The optimum production conditions were neutral $\mathrm{pH}$ and $35^{\circ} \mathrm{C}$. The induction of xylanases and $\alpha$-amylase are substrate dependent.

\section{ACKNOWLEDGMENTS}

None.

\section{CONFLICT OF INTEREST}

The authors declare that there is no conflict of interest.

\section{AUTHORS' CONTRIBUTION}

$A H, A M M$ and HAS designed the experiments. HAT, HAS and NAS, KAM, KAA performed the experiments. SRZA, and JAA-H analyzed the data. $A H, A M M$ wrote the manuscript. All authors read and approved the manuscript.

\section{FUNDING}

None.

\section{DATA AVAILABILITY}

All datasets generated or analyzed during this study are included in the manuscript.

\section{ETHICS STATEMENT}

Not applicable.

\section{REFERENCES}

1. Saini R, Saini HS, Dahiya A. Amylases: Characteristics and industrial applications. J Pharmacogn Phytochem. 2017;6(4):1865-1871.

2. Pandey A, Nigam P, Soccol CR, Soccol VT, Singh D, Mohan R. Advances in microbial amylases. Biotechnol Appl Biochem. 2000;31(2):135-152. doi: 10.1042/ BA19990073

3. Shariq M, Sohail M. Application of Candida tropicalis MK-160 for the production of xylanase and ethanol. J King Saud Univ Sci. 2019;31(4):1189-1194. doi: 10.1016/j.jksus.2018.04.009

4. Singh V, Pandey VC, Agrawal S. Potential of Laceyella sacchari strain B42 crude xylanase in biobleaching of kraft pulp. Afr J Mycol Biotechnol. 2013;12(6).

5. Patel S, Savanth V. Review on fungal xylanases and their applications. International Journal of Advanced Research. 2015;3(3):311-315.

6. Ali UF, Ibrahim ZM, Isaac GS. Ethanol and xylitol production from xylanase broth of Thermomyces lanuginosus grown on some lignocellulosic wastes using Candida tropicalis EMCC2. Life Science Journal. 2013;10(1):968-978.

7. Walia A, Guleria S, Mehta P, Chauhan A, Parkash J. Microbial xylanases and their industrial application in pulp and paper biobleaching: a review. 3 Biotech. 2017;7(1):11. doi: 10.1007/s13205-016-0584-6

8. Lara CA, Santos RO, Cadete RM, et al. Identification and characterisation of xylanolytic yeasts isolated from decaying wood and sugarcane bagasse in Brazil. Antonie van Leeuwenhoek. 2014;105(6):1107-1119. doi: 10.1007/s10482-014-0172-x

9. Lopes F, Motta F, Andrade C, Rodrigues M, MaugeriFilho F. Thermo-stable xylanases from non conventional yeasts. J Microb Biochem Technol. 2011;3(3):36-42.

10. Ozcan S, Kotter P, Ciciary M. Xylan-hydrolysing enzymes of the yeast Pichia stipitis. Appl Microbiol Biotechnol. 1991;36(2):190-195. doi: 10.1007/BF00164418

11. Gomes FC, Safar SV, Marques AR, et al. The diversity and extracellular enzymatic activities of yeasts isolated from water tanks of Vriesea minarum, an endangered bromeliad species in Brazil, and the description of Occultifur brasiliensis fa, sp. nov. Antonie van Leeuwenhoek. 2015;107(2):597-611. doi: 10.1007/ s10482-014-0356-4

12. Walia A, Mehta P, Chauhan A, Kulshrestha S, Shirkot C. Purification and characterization of cellulase-free low molecular weight endo $\beta-1,4$ xylanase from an alkalophilic Cellulosimicrobium cellulans CKMX1 
isolated from mushroom compost. World J Microbiol Biotechnol. 2014;30(10):2597-2608. doi: 10.1007/ s11274-014-1683-3

13. Rajagopalan G, Krishnan C. $\alpha$-Amylase production from catabolite derepressed Bacillus subtilis KCC103 utilizing sugarcane bagasse hydrolysate. Bioresource Technol. 2008;99(8):3044-3050. doi: 10.1016/j. biortech.2007.06.001

14. Gupta R, Gigras P, Mohapatra H, Goswami VK, Chauhan B. Microbial $\alpha$-amylases: a biotechnological perspective. Process Biochemistry. 2003;38(11):15991616. doi: 10.1016/S0032-9592(03)00053-0

15. Kandra L. $\alpha$-Amylases of medical and industrial importance. Journal of Molecular Structure: THEOCHEM. 2003;666:487-498. doi: 10.1016/j. theochem.2003.08.073

16. Simair AA, Qureshi AS, Khushk I, et al. Production and partial characterization of $\alpha$-amylase enzyme from Bacillus sp. BCC 01-50 and potential applications. BioMed Res Int. 2017;2017:9173040. doi: 10.1155/2017/9173040

17. Couto SR, Sanroman MA. Application of solid-state fermentation to food industry-a review. Journal of Food Engineering. 2006;76(3):291-302. doi: 10.1016/j. jfoodeng.2005.05.022

18. Gangadharan D, Sivaramakrishnan S, Nampoothiri KM, Sukumaran RK, Pandey A. Response surface methodology for the optimization of alpha amylase production by Bacillus amyloliquefaciens. Bioresource Technol. 2008;99(11):4597-4602. doi: 10.1016/j. biortech.2007.07.028

19. Souza PMd. Application of microbial $\alpha$-amylase in industry-A review. Braz J Microbiol. 2010;41(4):850861. doi: $10.1590 /$ S1517-83822010000400004

20. Hesham A. New safety and rapid method for extraction of genomic DNA from bacteria and yeast strains suitable for PCR amplifications. J Pure Appl Microbiol. 2014;8(1):383-388.

21. Castro G, Ferrero M, Mendez B, Sineriz F. Screening and selection of bacteria with high amylolytic activity. Acta Biotechnologica. 1993;13(2):197-201. doi: 10.1002/ abio. 370130220

22. Kurtzman CP, Robnett CJ. Identification and phylogeny of ascomycetous yeasts from analysis of nuclear large subunit (26S) ribosomal DNA partial sequences. Antonie van Leeuwenhoek. 1998;73(4):331-371. doi: 10.1023/A:1001761008817

23. Hesham AE-L, Alrumman SA, ALQahtani ADS. Degradation of toluene hydrocarbon by isolated yeast strains: molecular genetic approaches for identification and characterization. Russian Journal of Genetics. 2018;54(8):933-943. doi: 10.1134/ S1022795418080070

24. Faria NT, Marques S, Ferreira FC, Fonseca C. Production of xylanolytic enzymes by Moesziomyces spp. using xylose, xylan and brewery's spent grain as substrates. New Biotechnology. 2019;49:137-143. doi: 10.1016/j. nbt.2018.11.001

25. Miller GL. Use of dinitrosalicylic acid reagent for determination of reducing sugar. Analytical Chemistry. 1959;31(3):426-428. doi: 10.1021/ac60147a030

26. Kumari D, Abideen Z, Sohail M, et al. Plant cell-wall hydrolyzing enzymes from indigenously isolated fungi grown on conventional and novel natural substrates. Pak J Bot. 2017;49(2):745-750.

27. Shahryari Z, Fazaelipoor MH, Ghasemi Y, Lennartsson PR, Taherzadeh MJ. Amylase and xylanase from edible fungus Neurospora intermedia: production and characterization. Molecules. 2019;24(4):721. doi: 10.3390/molecules24040721

28. Hesham A, Alrumman S, Al-Dayel M, Salah H. Screening and genetic identification of acidic and neutral protease-producing yeasts strains by 26S rRNA gene sequencing. Cytology and Genetics. 2017;51(3):221229. doi: $10.3103 /$ S0095452717030033

29. Wang S-L, Liang Y-C, Liang T-W. Purification and characterization of a novel alkali-stable $\alpha$-amylase from Chryseobacterium taeanense TKU001, and application in antioxidant and prebiotic. Process Biochemistry. 2011;46(3):745-750. doi: 10.1016/j. procbio.2010.11.022

30. Florencio C, Couri S, Farinas CS. Correlation between agar plate screening and solid-state fermentation for the prediction of cellulase production by Trichoderma strains. Enzyme Research. 2012;2012:793708. doi: $10.1155 / 2012 / 793708$

31. Otero D, Cadaval C, Teixeira L, Rosa C, Sanzo A, Kalil $\mathrm{S}$. Screening of yeasts capable of producing cellulasefree xylanase. African Journal of Biotechnology. 2015;14(23):1961-1969. doi: 10.5897/AJB2015.14476

32. Hong SG, Chun J, Oh HW, Bae KS. Metschnikowia koreensis sp. nov., a novel yeast species isolated from flowers in Korea. Int J Syst Evol Microbiol. 2001;51(5):1927-1931. doi: 10.1099/00207713-515-1927

33. Herzberg $M$, Fischer $R$, Titze A. Conflicting results obtained by RAPD-PCR and large-subunit rDNA sequences in determining and comparing yeast strains isolated from flowers: a comparison of two methods. Int J Syst Evol Microbiol. 2002;52(4):1423-1433. doi: 10.1099/00207713-52-4-1423

34. Hesham AEL, Khan S, Liu X, Zhang Y, Wang Z, Yang M. Application of PCR-DGGE to analyse the yeast population dynamics in slurry reactors during degradation of polycyclic aromatic hydrocarbons in weathered oil. Yeast. 2006;23(12):879-887. doi: 10.1002/yea.1401

35. Abliz P, Fukushima K, Takizawa K, Nishimura K. Identification of pathogenic dematiaceous fungi and related taxa based on large subunit ribosomal DNA D1/D2 domain sequence analysis. FEMS Immunol Med Microbiol. 2004;40(1):41-49. doi: 10.1016/S09288244(03)00275-X

36. Liu Z, Hu Z, Zheng Y, Shen Y. Optimization of cultivation conditions for the production of 1, 3-dihydroxyacetone by Pichia membranifaciens using response surface methodology. Biochemical engineering journal. 2008;38(3):285-291. doi: 10.1016/j.bej.2007.07.015

37. Bautista-Gallego J, Rodriguez-Gomez F, Barrio E, Querol A, Garrido-Fernandez A, Arroyo-Lopez FN. Exploring the yeast biodiversity of green table olive industrial fermentations for technological applications. Int J Food Microbiol. 2011;147(2):89-96. doi: 10.1016/j. ijfoodmicro.2011.03.013 
38. Romero A, Mateo J, Maicas S. Characterization of an ethanol-tolerant 1, 4- $\beta$-xylosidase produced by Pichia membranifaciens. Lett Appl Microbiol. 2012;55(5):354361. doi: 10.1111/j.1472-765X.2012.03297.x

39. Gurudeeban $S$, Satyavani K, Ramanathan T. Production of extra cellular $\alpha$-amylase using Bacillus megaterium isolated from white Mangrove (Avicennia marina). Asian Journal of Biotechnology. 2011;3(3):310-316. doi: 10.3923/ajbkr.2011.310.316

40. Vijayaraghavan P, Remya C, Vincent SP. Production of [alpha]-Amylase by Rhizopus microsporus using Agricultural By-products in Solid State Fermentation. Research Journal of Microbiology. 2011;6(4):366-375. doi: 10.3923/jm.2011.366.375

41. Sandrim V, Rizzatti A, Terenzi H, Jorge J, Milagres A, Polizeli M. Purification and biochemical characterization of two xylanases produced by Aspergillus caespitosus and their potential for kraft pulp bleaching. Process Biochemistry. 2005;40(5):1823-1828. doi: 10.1016/j. procbio.2004.06.061

42. Mohamed SA, Azhar El, Ba-Akdah MM, Tashk NR, Kumosani TA. Production, purification and characterization of-amylase from Trichoderma harzianum grown on mandarin peel. Afr J Microbiol Res. 2011;5(8):930-940. doi: 10.5897/AJMR10.890

43. ChakrabortyS, Khopade A, Biao R, et al. Characterization and stability studies on surfactant, detergent and oxidant stable $\alpha$-amylase from marine haloalkaliphilic Saccharopolyspora sp. A9. Journal of Molecular Catalysis B: Enzymatic. 2011;68(1):52-58. doi: 10.1016/j.molcatb.2010.09.009

44. Vijayaraghavan P, Kalaiyarasi M, Vincent SGP. Cow dung is an ideal fermentation medium for amylase production in solid-state fermentation by Bacillus cereus. J Genet Eng Biotechnol. 2015;13(2):111-117. doi: 10.1016/j.jgeb.2015.09.004
45. Abdullah R, Shaheen N, Iqtedar M, Naz S, Iftikhar T. Optimization of cultural conditions for the production of alpha amylase by Aspergillus niger (BTM-26) in solid state fermentation. Pak J Bot. 2014;46(3):1071-1078.

46. Walia A, Mehta P, Chauhan A, Shirkot CK. Optimization of cellulase-free xylanase production by alkalophilic Cellulosimicrobium sp. CKMX in solid-state fermentation of apple pomace using central composite design and response surface methodology. Annals of Microbiology. 2013;63(1):187-198. doi: 10.1007/ s13213-012-0460-5

47. Yang S, Yan Q, Jiang Z, Li L, Tian H, Wang Y. High-level of xylanase production by the thermophilic Paecilomyces themophila J18 on wheat straw in solid-state fermentation. Bioresource Technol. 2006;97(15):17941800. doi: 10.1016/j.biortech.2005.09.007

48. Yadav P, Maharjan J, Korpole S, et al. Production, purification, and characterization of thermostable alkaline xylanase from Anoxybacillus kamchatkensis NASTPD13. Front Bioeng Biotechnol. 2018;6:65. doi: 10.3389/fbioe.2018.00065

49. Lu F, Lu M, Lu Z, Bie X, Zhao H, Wang Y. Purification and characterization of xylanase from Aspergillus ficuum AF-98. Bioresource Technol. 2008;99(13):5938-5941. doi: 10.1016/j.biortech.2007.10.051

50. Wanderley KJ, Torres FA, Moraes LM, Ulhoa CJ. Biochemical characterization of $\alpha$-amylase from the yeast Cryptococcus flavus. FEMS Microbiol Lett. 2004;231(2):165-169. doi: 10.1016/S03781097(03)00955-8

51. Prieto JA, Bort BR, Martinez J, Randez-Gil F, Sanz P, Buesa $C$. Purification and characterization of a new $\alpha$-amylase of intermediate thermal stability from the yeast Lipomyces kononenkoae. Biochem Cell Biol. 1995;73(1-2):41-49. doi: 10.1139/o95-005 